\title{
CERAMIC PROPERTIES OF PUGU KAOLIN CLAYS. PART I: POROSITY AND MODULUS OF RUPTURE
}

\author{
Leonard D. Akwilapo $^{1 *}$ and Kjell Wiik ${ }^{2}$ \\ ${ }^{1}$ Department of Chemistry, University of Dar es Salaam, P.O. Box 35061, Dar es Salaam, \\ Tanzania \\ ${ }^{2}$ Department of Chemistry, Norwegian University of Science and Technology, N-7491, \\ Trondheim, Norway
}

(Received December 10, 2002; revised May 28, 2003)

\begin{abstract}
The utilisation of Pugu kaolin clay as a raw material in porcelain has been tested by laboratory scale experiments. Physical characteristics of the clay have shown it to be of satisfactory quality and comparable to commercial clays found elsewhere. The chemical analysis has indicated the presence of high levels of iron oxide $(\sim 1.43 \%)$ which could adversely affect the translucency of whitewares. The "as mined" material could be suitable for ceramics that do not require high brightness specifications, such as stoneware and sanitary ware. The level of this oxide can, however, be reduced by appropriate means to give a relatively cleaner product that could be excellent for other types of whiteware products.

Porcelain materials prepared using Pugu kaolin clay have shown to have similar properties as those prepared using other standard kaolin clays. The bulk density and flexural strength of the fired masses increase with firing temperature to a maximum at the soak temperature of $1200{ }^{\circ} \mathrm{C}$. Beyond this soak temperature the flexural strength decreases. The decrease in strength is attributable to bloating which takes place as gasses are expelled from the matrix. Strictly firing procedures should be enforced in order to obtain a porcelain material of required strength.
\end{abstract}

KEY WORDS: Kaolin clay, Ceramic properties, Porcelain materials, Bulk density, Sintering, Modulus of rupture, Bloating

\section{INTRODUCTION}

There are numerous kaolin deposits in Tanzania but those which are important in quantitative terms are the Pugu, Malangali and Chimala deposits [1]. The Pugu kaolin deposit is believed to be the largest in Africa [2]. These deposits differ in a number of ways: e.g. the type and amount of impurities, colour, mineralogical content and nature, plasticity, and the fired characteristics. As with clays of any origin, the above properties are expected to influence the ceramic and refractory properties of the clays. At present some Tanzanian clays are being used in "as mined" state for production of building bricks and roofing tiles [3]. However up to now no deposit has been systematically and exhaustively investigated. Consequently, very few scientific data are available on which to base plans and predictions for large scale, long term commercial development. Despite this fact, however, many of the larger deposits are considered to be viable in terms of the supply tonnage.

The Pugu kaolin deposit is of sedimentary origin similar to the Cretaceous kaolin of South Carolina and Georgia in the USA [2]. Two types of kaolinitic sandstones have been distinguished, the soft friable sandstone and the hard stratified sandstone [4]. Further discussion based on the kaolin from this deposit and the description of the two types of sandstones present can be found elsewhere $[5,6]$.

*Corresponding author. E-mail: akwilapo@chem.udsm.ac.tz 
In this series of contributions, the ceramic properties of Pugu kaolin clay are presented, focusing on its usability in the porcelain industry. In part I of this series the relationship between the porosity and flexural strength is investigated and reported. Typical porcelain recipes have been used to reveal the fired characteristics of the end products. Industrial grade quartz and feldspar are used throughout the study.

Porcelain is a vitrified product of mixtures of clay, quartz and feldspar. It is one of the most widely used and studied materials in the whole family of ceramics. A typical porcelain composition will consist of $50 \%$ clay, $25 \%$ quartz and $25 \%$ feldspar. China clay imparts rigidity to the ware and feldspar, as a flux provides a glassy phase in the microstructure. Quartz on the other hand lowers both drying and firing shrinkage and imparts rigidity to the wares. Mullite and glass constitute the major phases of porcelain materials. Other constituents, in minor levels are quartz, cristobalite, tridymite and corundum.

The physical properties of whiteware materials, which also include porcelains, depend on the microstructure as well as the phase distribution developed during the firing process. These two properties depend on the chemical composition of the raw materials, the preparation method and the time and temperature of firing $[7,8]$.

It has been reported that the clay from the Pugu deposit has shown properties satisfying the necessary conditions for application in the porcelain industries $[9,10]$. However this conclusion is based on very insufficient data and thus its potential for large-scale industrial activity is not yet ascertained.

Lynne et al. [10] made an investigation on a number of Tanzanian ceramic raw materials, among them the kaolin clay from the Pugu deposit. The chemical and physical measurements performed suggested that the material was suitable for ceramic production. However due to the lack of sufficient amounts of the materials it was not possible to evaluate the physical and chemical properties through actual ceramic production tests. Evaluation on one ceramic composition gave the optimal firing temperature of approximately $1280{ }^{\circ} \mathrm{C}$ with a firing interval of about $70{ }^{\circ} \mathrm{C}$. The test showed the presence of some coloration, which usually indicates the action of iron in the materials. The plastic property of the kaolin, as determined by the Atterberg Number Method, was reported to be of high degree and sufficient for ceramic production. It was concluded that the kaolin belongs to the upper range of plasticity and accordingly it should work satisfactorily in the production of ceramics. Its shrinkage, however, was relatively high and therefore posing a potential hazard of cracking during fabrication.

\section{EXPERIMENTAL}

Batch compositions typical of those used in the whiteware industries were chosen from the primary mullite field in the silica-alumina-alkali phase equilibrium diagram (Figure 1). Four different body compositions were prepared, these are indicated in Table 1. The body formulations were mixed with given volumes of water so that the resulting slip contains $28 \%$ water. Dolaflux $0.05 \%$ by weight was added to act as a deflocculant. The mixtures were ballmilled for 24 hours to allow intimate mixing and consequently increasing the probability of obtaining a homogeneous body. This was aimed at increasing the number of contacts between particles of different mineralogical species, a process known to increase the rate of the reactions at higher temperatures [11]. The slips were then casted into bars of $17 \mathrm{~cm} \mathrm{x} 1.5 \mathrm{~cm} \times 0.5 \mathrm{~cm}$ in plaster moulds. The bars were dried in open air for 24 hours and then in a laboratory oven at 110 $\pm 10{ }^{\circ} \mathrm{C}$ for 48 hours.

The dried samples were fired at the rate of $300{ }^{\circ} \mathrm{C}$ per hour to a predetermined soak temperature and held for 8 hours. The selected heating rate is considered to be optimal in avoiding surface cracking which is known to occur due to excessive surface drying. At standard 
heat treatment of these bodies, nearly all of the vitrifying action takes place at temperature above $1100{ }^{\circ} \mathrm{C}$, thus the rate of heating and cooling below this temperature was not closely controlled. However, the cooling rate between 600 and $500{ }^{\circ} \mathrm{C}$ was reduced to $50{ }^{\circ} \mathrm{C}$ per hour. This was aimed at reducing the damage that could be caused by the $\beta \rightarrow \alpha$-quartz transition, occurring at $595^{\circ} \mathrm{C}$.

The chemical composition and the loss on ignition of the raw materials used are given in Table 2. In Table 3 the overview of the grain size distributions of feldspar and quartz are presented. The grain size distribution of Pugu kaolin is shown in Figure 2.

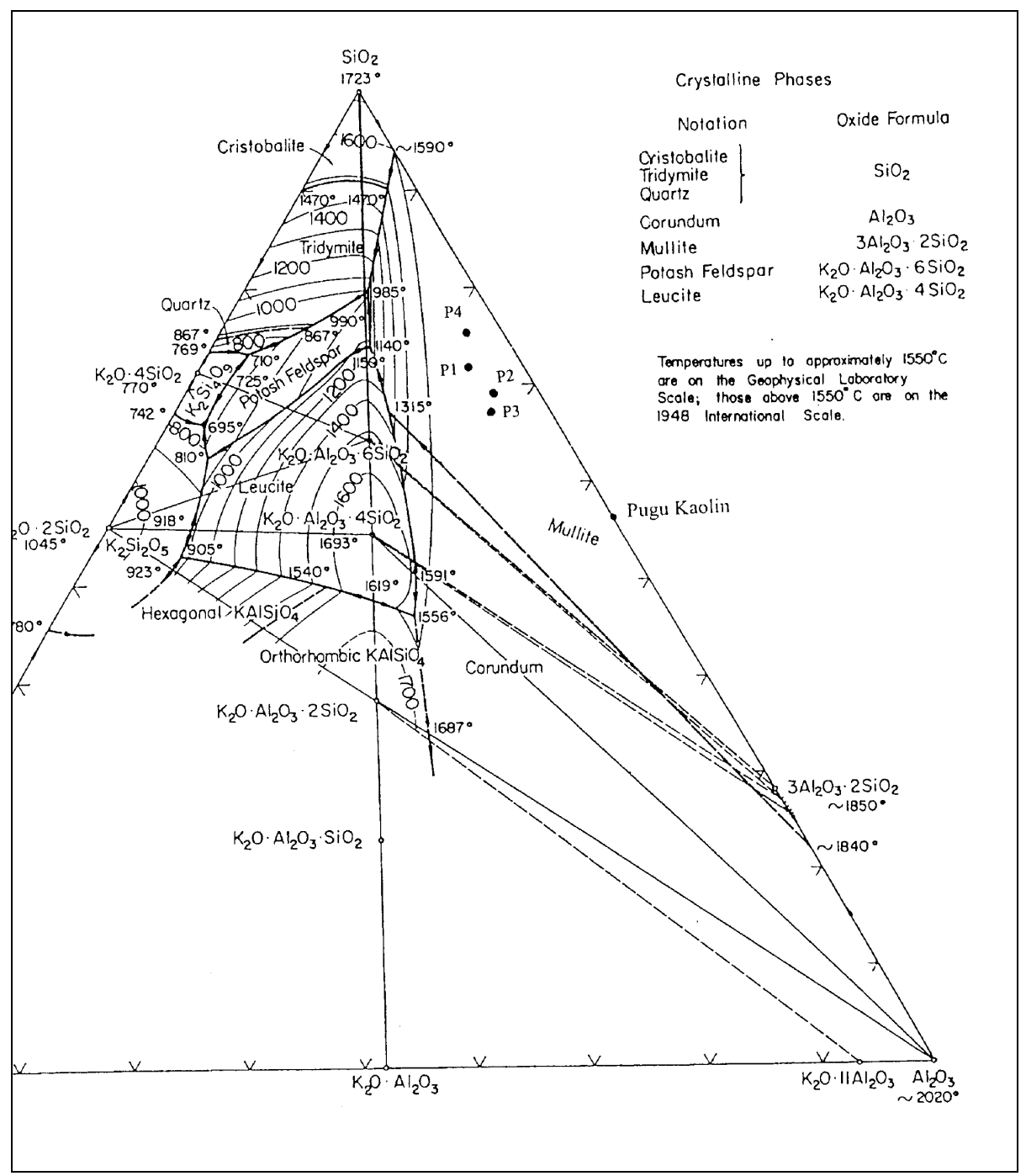

Figure1. Compositions of porcelain mixtures $\mathrm{P} 1_{(\mathrm{K} 40-\mathrm{F} 30-\mathrm{Q} 30)}, \mathrm{P} 2_{(\mathrm{K} 50-\mathrm{F} 25-\mathrm{Q} 25)}, \mathrm{P} 3_{(\mathrm{K} 50-\mathrm{F} 30-\mathrm{Q} 20)}$ and $\mathrm{P}_{\text {(K40-F20-Q40) }}$ displayed on the $\mathrm{K}_{2} \mathrm{O}-\mathrm{Al}_{2} \mathrm{O}_{3}-\mathrm{SiO}_{2}$ phase diagram (taken from Levin et al. [9]).

Bull. Chem. Soc. Ethiop. 2003, 17(2) 
The bulk densities of the fired bars were determined by the Archimedes principle as described in ISO 5017:1988. The modulus of rupture (MOR) of the test bars was measured with the Digimaxx C-20 in a three point bending test. The distance between the bearing edges was 70 $\mathrm{mm}$. The load was applied uniformly at a right angle to the rectangular bars at the rate of 0.05 $\mathrm{kN} / \mathrm{s}$ until failure occurred. The MOR was calculated from the formula:

$$
M=\frac{3 P L}{2 b d^{2}}
$$

where $\mathrm{M}=$ modulus of rupture $(\mathrm{MPa}), \mathrm{P}=$ load at rupture $(\mathrm{N}), \mathrm{L}=$ distance between supports $(\mathrm{mm}), \mathrm{b}=$ width of the specimen $(\mathrm{mm}), \mathrm{d}=$ thickness of the specimen $(\mathrm{mm})$.

Table 1. The percentage compositions of the raw batches.

\begin{tabular}{|l|l|l|l|l|}
\hline Component & P1 & P2 & P3 & P4 \\
\hline Pugu kaolin & 40 & 50 & 50 & 40 \\
\hline Feldspar NGP & 30 & 25 & 30 & 20 \\
\hline Quartz NGQ & 30 & 25 & 20 & 40 \\
\hline
\end{tabular}

Table 2. Chemical composition in percentages.

\begin{tabular}{|l|l|l|l|l|l|l|l|l|l|}
\hline Component & $\mathrm{SiO}_{2}$ & $\mathrm{Al}_{2} \mathrm{O}_{3}$ & $\mathrm{Fe}_{2} \mathrm{O}_{3}$ & $\mathrm{TiO}_{2}$ & $\mathrm{CaO}$ & $\mathrm{MgO}$ & $\mathrm{K}_{2} \mathrm{O}$ & $\mathrm{Na}_{2} \mathrm{O}$ & $\mathrm{LOI}$ \\
\hline Pugu kaolin & 46 & 36 & 1.43 & 0.87 & 0.24 & 0.62 & 0.31 & 0.19 & 10.5 \\
\hline Feldspar (NGP 200) & 66 & 18.5 & 0.07 & - & 0.4 & - & 11.80 & 2.90 & 0.15 \\
\hline Quartz (NGQ 250) & 99.6 & 0.25 & 0.01 & - & - & - & - & - & 0,10 \\
\hline
\end{tabular}

Table 3. Particle size distribution of feldspar and quartz (in percentages).

\begin{tabular}{|l|l|l|l|l|}
\hline Component & $<74 \mu \mathrm{m}$ & $<44 \mu \mathrm{m}$ & $<20 \mu \mathrm{m}$ & $<10 \mu \mathrm{m}$ \\
\hline Feldspar (NGP 200) & $98-99$ & $88-90$ & $58-62$ & $38-42$ \\
\hline Quartz (NGQ 250) & $95-99$ & $92-94$ & $64-68$ & $36-40$ \\
\hline
\end{tabular}

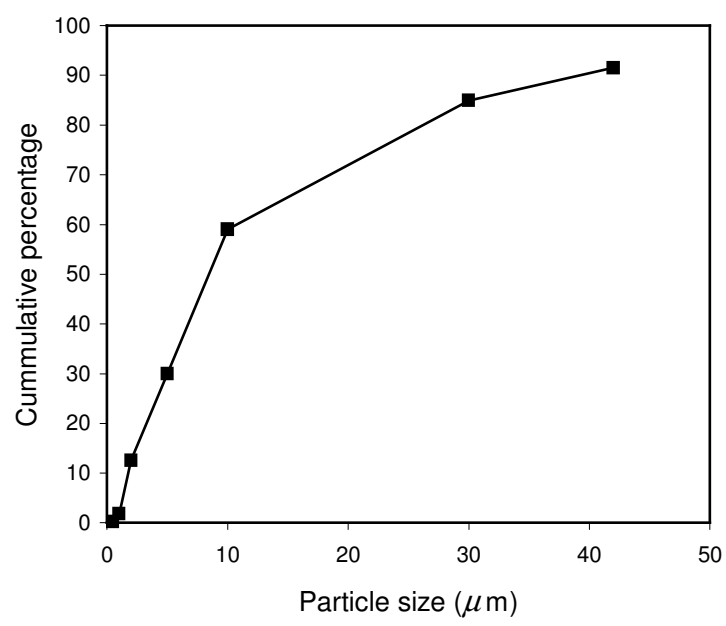

Figure 2. Cumulative particle size distribution of Pugu kaolin clay.

Bull. Chem. Soc. Ethiop. 2003, 17(2) 


\section{RESULTS AND DISCUSSION}

The variation of bulk density with soak temperature is shown in Figure 3. There is a clear indication that the bulk density increases with the firing temperature up to a maximum and then decreases as the soak temperature is increased further. The maximum bulk density is obtained at $1200{ }^{\circ} \mathrm{C}$, which is $2.5 \mathrm{~g} / \mathrm{cc}$. It has been reported that the bulk density reaches its maximum at the temperature where there is enough liquid phase to block the open porosity. It will be expected, therefore, that this temperature will vary inversely with the relative amount of feldspar. This is because the feldspar component melts at a relatively low temperature and, therefore, acts as a flux. Compositions P1, P2 and P3, having relatively high percentages of feldspar, produce products of high density at $1200{ }^{\circ} \mathrm{C}$ while sample P4 of low feldspar content shows a lower density. The decrease of the bulk density at higher firing temperature is believed to be caused by bloating. This is mainly a result of the expansion of gases enclosed in the matrix as the temperature is elevated. SEM image of a porcelain material fired at $1300{ }^{\circ} \mathrm{C}$ depicting the effect of bloating is shown in Figure 4. Bloating is principally caused by expansion of gasses enclosed in pores. In some cases, it can also be caused by the expulsion of oxygen obtained after the decomposition of ferrous oxide [12], $3 \mathrm{Fe}_{2} \mathrm{O}_{3} \rightarrow 2 \mathrm{Fe}_{3} \mathrm{O}_{4}+1 / 2 \mathrm{O}_{2}$.

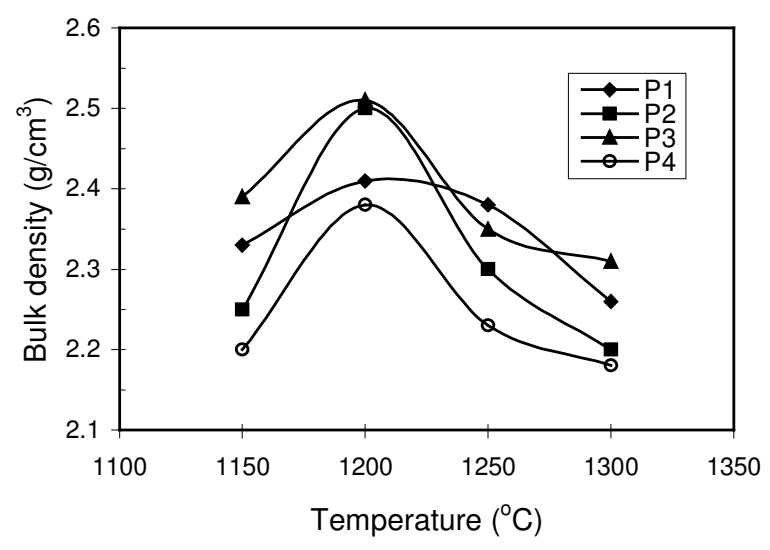

Figure 3. The variation of bulk density with peak temperature for the porcelain samples.

Bloating of porcelain bodies gives a demand for a specification of a firing temperature range within which bloating can not occur. Outside this range bloating is responsible for the decreasing strength of porcelain materials [13]. Generally, on firing, the bulk density of porcelain bodies in the kaolin-feldspar-quartz system increases to a maximum and then decreases as the closed porosity increases. As a result, the firing temperature ranges for successful firing of porcelain bodies are relatively limited and the optimum vitrification is achieved when the apparent porosity reaches a minimum value, which is normally zero or just close to it. Kobayashi et al [8] have divided this sintering behaviour of porcelain into two categories, the temperatures between 1100 and $1200{ }^{\circ} \mathrm{C}$ exhibiting densification and that between 1250 and $1350{ }^{\circ} \mathrm{C}$ exhibiting bloating. 


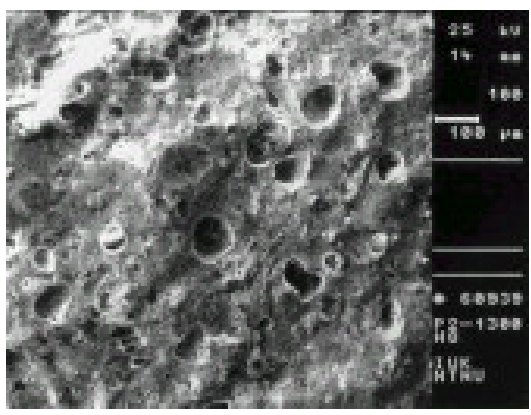

Figure 4. SEM image of porcelain sample P2 fired at $1300{ }^{\circ} \mathrm{C}$ for 8 hours depicting the effect of bloating.

Figure 5 shows the relationship between the modulus of rupture and the peak firing temperature. The MOR is seen to vary proportionally with temperature up to a maximum value and then decrease with further heating. The maximum values of MOR are attained at 1200 and $1250{ }^{\circ} \mathrm{C}$, depending on the composition of the porcelain prepared. As expected the maximum MOR is attained when the bulk density is at minimum. This was also reported in the work of Norris et al [12]. The authors observed that, for siliceous porcelains, a maximum bending strength is developed when the apparent porosity decreases to a minimum which in most cases is zero.

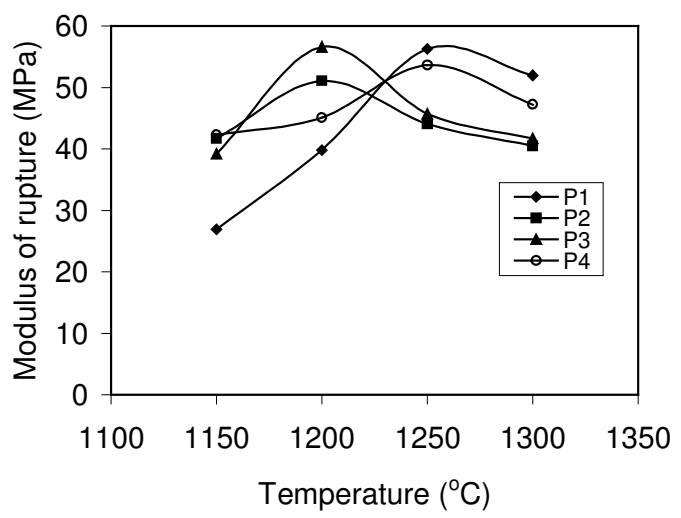

Figure 5. The variation of MOR with the firing temperature.

The results in this work suggest that the temperature for maximum modulus of rupture is 50 ${ }^{\circ} \mathrm{C}$ below the temperature for complete vitrification (Figures 5 and 6). Kobayashi et al. [13] have attributed this increase in strength to the formation of a dense and thin layer close to the surface of the fired samples. This will occur at temperatures close to the temperature when the vitrification process reaches its maximum. However, the actual temperature will depend on the composition of the material in question. In any case however this is the temperature around which the apparent porosity of most porcelain compositions approach zero, which indicates that much liquid phase is formed and consequently a considerable amount of the glass phase will be available after cooling. This component, is primarily, known to control the strength in porcelains. In fact glass formation acts to densify the structure by liquid phase sintering. The 
driving force for densification is the lowering of surface free energy by the elimination of interfaces. In Figure 7 the significance of feldspar content is depicted, notable is the fact that the bulk density increases sharply due to the formation of a large amount of glass phase for compositions with high contents of feldspar i.e. samples P1 and P3.

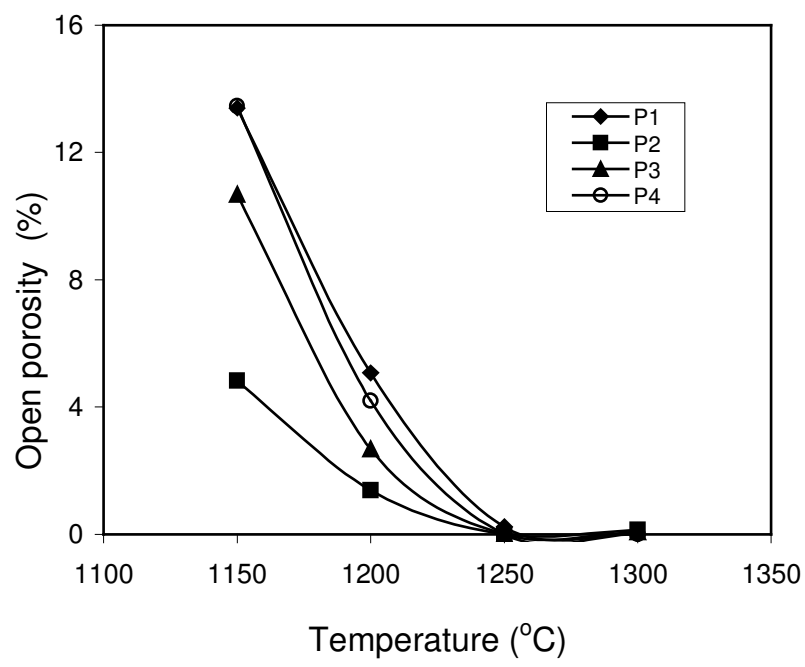

Figure 6. Variation of open porosity with the firing temperature for porcelain.

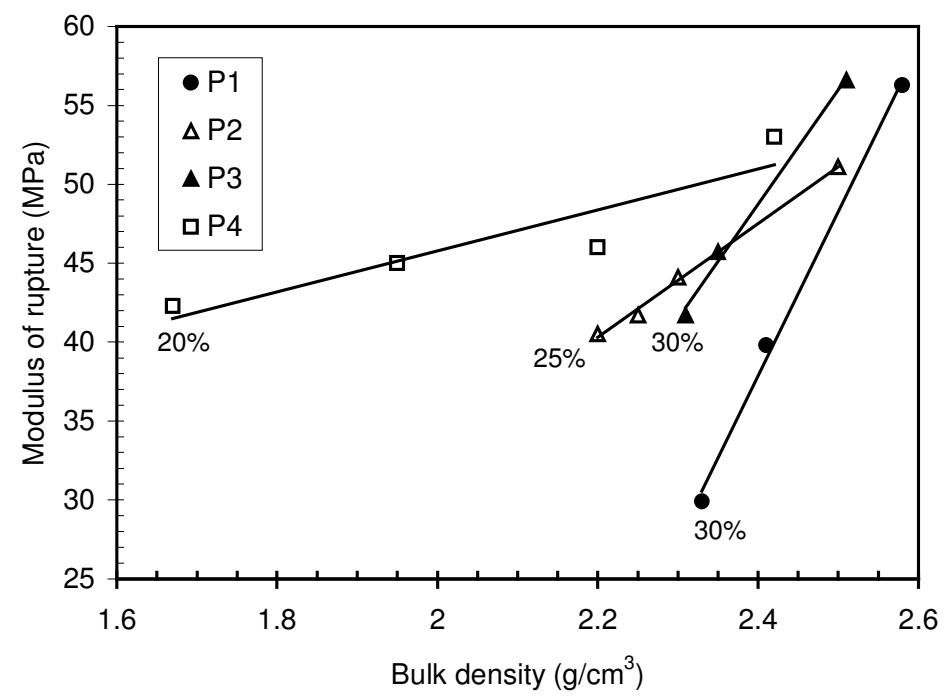

Figure 7. The dependence of the modulus of rupture on the bulk density for mixtures containing varying amounts of feldspar.

Bull. Chem. Soc. Ethiop. 2003, 17(2) 


\section{CONCLUSION}

The aim of this work has been to evaluate the suitability of the Pugu kaolin in the fabrication of porcelain materials. The raw material has shown to follow the general properties of china clay as far as their role in porcelain is concerned. The bulk density of the fired bars has shown to increase up to a maximum before decreasing as a result of bloating. The temperature for maximum bulk density is found to be around $1200{ }^{\circ} \mathrm{C}$, the actual temperature depending on the composition of the material. On the other hand, the modulus of rupture, considered hereby as the measure of the strength developed in the matrix, has been shown to increase proportionally with the bulk density. Both quantities attain their maximum values at the same soak temperature. Beyond the soak temperature for maximum strength the relationship is not so obvious. This, however, is understandable since the open porosity will no longer be responsible for controlling the strength. As the open porosity is already at its minimum value, other properties will influence the strength of the material. Such properties include; the closed porosity, the crystalline and glass phase contents, shape and preferred orientations of the grains as well as the heterogeneity and spatial orientation of the pores. In the region studied, it has been shown that the material is suitable for application in the fabrication of porcelain materials.

\section{REFERENCES}

1. STAMICO, State Mining Corporation Annual Report and Accounts, Dar es Salaam, 1988.

2. Lobitzer, H.; Giacomini, R.; Muller, H.W.; Notstaller, R.; Schwaighofer, B. Geology and Utilisation of the Pugu Hills Kaolin Deposit, Tanzania, Institute fur Geologie der Universitat: Wien; 1982.

3. Mwakarukwa, G.M. Geologic and Economic Aspects of Clays in Tanzania in Development of the Non-metallic Minerals and the Silicate Industry in Tanzania, Kimambo, R.H. (Ed.); East African Publication Ltd: Dar es Salaam: 1988.

4. Truter, A.A. Kaolin Deposits in the Pugu Hills and Limestone Deposits at Msanga Unpub. Report Geol. Surv. Tanganyika. Report No. AAT/1, Dodoma, 1947.

5. Mutakyahwa, M.K.D. M.Sc. Thesis, University of Dar es Salaam, 1983.

6. Robertson, R.H.S.; Brindley, G.W.; MacKenzie, R.C. Am. Mineral. 1954, 39, 113.

7. Maity, S.; Mukhopadhyay, T.K.; Sarkar, B.K. Interceram. 1996, 45, 397.

8. Kobayashi,Y.; Ohira, O.; Satoh, T.; Kato, E. J. Ceram. Soc. Jpn. (Int. Ed.) 1994, 102, 99.

9. Levin, E.M.; Robbins, C.R.; McMurdie, H.F. Phase Diagrams for Ceramics Reser, M.K. (Ed.); American Ceramic Society: Columbus, Ohio; 1964.

10. Lynne, H.; Strand, G.; Lyng, S. Investigation of Ceramic Raw Materials from Tanzania, Project No. 7910 03, Sentralinstitute for Industriell Forskning, Oslo, 1980.

11. Funk, J.E.; Dinger, D.R. Predictive Process Control of Crowded Particulate Suspensions Applied to Ceramic Manufacturing, Kluwer Academic Publishers: Boston; 1994.

12. Norris, A.W.; Taylor, D.; Thorpe, I. Trans. J. Br. Ceram. Soc. 1979, 78, 102.

13. Kobayashi, Y.; Ohira, O.; Ohashi, Y.; Katoh, E. J. Ceram. Soc. Jpn. 1991, 99, 495. 